\title{
A new instrument to measure plot-scale runoff
}

\author{
R. D. Stewart ${ }^{1}$, Z. Liu ${ }^{2}$, D. E. Rupp ${ }^{3}$, C. W. Higgins ${ }^{2}$, and J. S. Selker ${ }^{2}$ \\ ${ }^{1}$ Crop and Soil Environmental Science Department, Virginia Polytechnic Institute and State University, Blacksburg, VA, USA \\ ${ }^{2}$ Biological \& Ecological Engineering Department, Oregon State University, Corvallis, OR, USA \\ ${ }^{3}$ Oregon Climate Change Research Institute, College of Earth, Ocean and Atmospheric Sciences, Oregon State University, \\ Corvallis, OR, USA
}

Correspondence to: R. D. Stewart (ryan.stewart@vt.edu)

Received: 26 September 2014 - Published in Geosci. Instrum. Method. Data Syst. Discuss.: 17 November 2014

Revised: 4 February 2015 - Accepted: 5 February 2015 - Published: 2 March 2015

\begin{abstract}
Accurate measurement of the amount and timing of surface runoff at multiple scales is needed to understand fundamental hydrological processes. At the plot scale (i.e., length scales on the order of 1-10 m) current methods for direct measurement of runoff either store the water in a collection vessel, which is not conducive to long-term monitoring studies, or utilize expensive installations such as largescale tipping buckets or flume/weir systems. We developed an alternative low-cost, robust and reliable instrument to measure runoff that we call the "Upwelling Bernoulli Tube" (UBeTube). The UBeTube instrument is a pipe with a slot machined in its side that is installed vertically at the base of a runoff collection system. The flow rate through the slot is inferred by measuring the water height within the pipe. The geometry of the slot can be modified to suit the range of flow rates expected for a given site; we demonstrate a slot geometry that is capable of measuring flow rates across more than 3 orders of magnitude (up to $300 \mathrm{~L} \mathrm{~min}^{-1}$ ) while requiring only $30 \mathrm{~cm}$ of hydraulic head. System accuracy is dependent on both the geometry of the slot and the accuracy of the water level measurements. Using a pressure sensor with $\pm 7 \mathrm{~mm}$ accuracy, the mean theoretical error for the demonstrated slot geometry was $\sim 17 \%$ (ranging from errors of more than $50 \%$ at low flow rates to less than $2 \%$ at high flow rates), while the observed error during validation was $1-25 \%$. A simple correction factor reduced this mean error to $0-14 \%$, and further reductions in error could be achieved through the use of taller, narrower slot dimensions (which requires greater head gradients to drive flow) or through more accurate water level measurements. The UBeTube device has been successfully employed in a long-term rainfall-runoff study, demonstrating the ability of the instrument to measure surface runoff across a range of flows and conditions.
\end{abstract}

\section{Introduction}

Surface runoff, or overland flow, is a fundamental process of interest in hydrology. Surface runoff generation can occur at multiple scales, ranging from small pools of excess water that propagate downhill to stream networks that drain large catchments (Horton, 1939; Betson, 1964; Hewlett and Hibbert, 1967; Dunne and Black, 1970; Goodrich et al., 1994; Van de Giesen et al., 2000; Stomph et al., 2001, 2002a; McDonnell, 2003; Descroix et al., 2007; Blume et al., 2008; McGuire and McDonnell, 2010; Ali et al., 2013; Jones et al., 2013; Radatz et al., 2013; Steenhuis et al., 2013; Blair et al., 2014; Stewart et al., 2014). Runoff is a primary cause of erosion and can drive nutrient losses from watersheds (Aksoy and Kavvas, 2005; Butler et al., 2008; Nearing et al., 2011). Accurate measurement of runoff quantity is therefore vital to understand the mechanisms and effects of overland flow.

A number of instruments have been used to quantify runoff. At the plot scale (encompassing lengths on the order of 1 to $10 \mathrm{~m}$ ), the most basic measurement method involves diverting flow to a barrel or similar structure (Hudson, 1993; Meals and Braun, 2006; Dosskey et al., 2007). Water quantity, chemistry and sediment measurements can then be taken on the collected water. This setup is typically inexpensive and easy to install, but requires that the barrels be periodically emptied if long-term monitoring is desired. Alternative systems have been designed to mitigate these problems, including dividing flow into multiple containers (Pinson et al., 2004), or using electronic water sensors (Srinivasan et al., 2000) or tipping buckets (Hashim et al., 1995; Yu et al., 1997; Zhao et al., 2001; Nehls et al., 2010). Flow dividers still necessitate the capture and storage of the runoff water, while the electronic sensor system only detects the presence 
or absence of surface flow. Tipping bucket systems are selfemptying and can be used for long-term deployments, but may have significant error at both low and high flow rates. For instance, the Belfort-type tipping bucket rain gauge was shown to have a per-minute accuracy of only $12 \mathrm{~mm} \mathrm{~h}^{-1}$, limiting its utility to monitor low flow events (Nystuen et al., 1996). Likewise, tipping bucket error can exceed $25 \%$ at flow rates greater than $150 \mathrm{~mm} \mathrm{~h}^{-1}$, due to non-linear instrument response (Nystuen et al., 1996; Humphrey et al., 1997; Nystuen, 1999; Stewart et al., 2012). These systems can also become fouled and/or clogged (Habib et al., 2001), which is a concern in high sediment environments.

V-notched weirs and flumes have also been used to measure runoff at the plot scale (Hashim et al., 1995; Radatz et al., 2013), as well as for measuring surface runoff in larger catchments (Hudson, 1993). However, these installations are often expensive, with a per-plot cost that can exceed USD 5000 (Pinson et al., 2004). Further, maintaining the required up-stream condition of the bed being well below the notch of the weir requires frequent maintenance in natural streams. Finally, Stomph et al. (2002b) designed a flowmeter to measure small discharge rates ( 2 to $60 \mathrm{~L} \mathrm{~min}^{-1}$ ), in which water enters into and then drains from a chamber filled with small circular orifices. While quite accurate in controlled laboratory conditions, the instrument is highly sensitive to temperature shifts (due to the use of an air pressure gauge to determine water height), and the orifice configuration needs to be varied depending on the expected range of flows; thus, the instrument is not well suited for many field conditions.

Seeing the need for a low-cost, reliable and accurate method for measuring runoff in the field, we developed a new instrument called the "Upwelling Bernoulli Tube", or "UBeTube" for short. Similar in function to a v-notch weir, the instrument is self-emptying, features no moving parts, and can be configured to minimize sensitivity to sedimentation. Our tested design possessed the ability to accurately measure flows as low as $0.05 \mathrm{~L} \mathrm{~min}^{-1}$ and up to $300 \mathrm{~L} \mathrm{~min}^{-1}$ (the latter roughly translating to a runoff rate of $200 \mathrm{~mm} \mathrm{~h}^{-1}$ from a $100 \mathrm{~m}^{2}$ plot), making it suitable for long-term monitoring studies. Best of all, the instrument can be constructed using commonly available, low-cost materials, which should enable its widespread usage in environmental monitoring studies.

\section{Methods}

\subsection{Instrument design}

The UBeTube design employed here consisted of a vertical $10 \mathrm{~cm}$ (4 inch) diameter pipe with a slot machined into one side (Fig. 1). Schedule 40 aluminum pipe (alloy 6063-T52, though others could be used with equal success) was employed, due to its relatively low cost, strength, rigidity, resistance to corrosion, and machinability. Schedule 40 or higher
PVC may also be used, although in our experience the lack of rigidity can make it difficult to accurately machine the slot, and thermal stability is of concern with plastics. The UBeTube pipe can then be attached to a runoff collection system through use of water-tight neoprene rubber gaskets or similar connection method.

We attached the runoff collection system to the bottom of the UBeTube instrument for several reasons:

1. the pressure head needed to drive flow into the pipe is reduced compared to having water enter through the top;

2. splashing due to incoming water, which causes pressure fluctuations, is minimized;

3. the runoff system piping can be buried below grade, which protects it, buffers temperature swings, and secures the system. Example installations are shown in Fig. 1a, b and c.

It should be noted that having the inflow arrive through the bottom of the pipe could create complicated backwater conditions within the runoff delivery pipe, which can alter the shape and timing of the runoff hydrograph. Thus, in certain situations, it may be preferable to have the inflow enter the UBeTube from the top.

The UBeTube instrument's machined slot can be any shape and dimension, providing the ability to accurately measure a wide range of discharge rates. Our example system used a slot formed by two superimposed trapezoids: the lower trapezoid had dimensions of $0.2 \mathrm{~cm}$ bottom width, $1 \mathrm{~cm}$ top width and $10 \mathrm{~cm}$ height, while the upper trapezoid had dimensions of $6 \mathrm{~cm}$ top width and $6 \mathrm{~cm}$ height (Fig. 1c). This allowed the system to be operated with less than $30 \mathrm{~cm}$ of pressure head.

By measuring the water height within the pipe, the volumetric flow rate of water through the trapezoidal slot can be calculated using Bernoulli's equation. Assuming steady-state conditions, the volumetric flow rate $(Q)$ of water through a slot formed from two superimposed trapezoids (such as is shown in Fig. 1c) can be calculated as follows: when $h_{0} \leq h \leq h_{1}$

$Q=\frac{2}{3} c w_{0} \sqrt{2 g} h^{3 / 2}+\frac{4}{15} c \frac{\left(w_{1}-w_{0}\right)}{h_{1}} \sqrt{2 g} h^{5 / 2}$,

when $h_{1}<h \leq h_{2}$

$$
\begin{gathered}
Q=\frac{2}{3} c w_{1} \sqrt{2 g}\left(h-h_{1}\right)^{3 / 2}+\frac{4}{15} c \frac{\left(w_{2}-w_{1}\right)}{\left(h_{2}-h_{1}\right)} \sqrt{2 g}\left(h-h_{1}\right)^{5 / 2} \\
+\frac{2}{3} c w_{0} \sqrt{2 g}\left(h^{3 / 2}-\left(h-h_{1}\right)^{3 / 2}\right) \\
+c \frac{\left(w_{1}-w_{0}\right)}{h_{1}} \sqrt{2 g}\left(\frac{4}{15} h^{5 / 2}+\frac{2}{5}\left(h-h_{1}\right)^{5 / 2}-\frac{2}{3} h\left(h-h_{1}\right)^{3 / 2}\right)
\end{gathered},
$$




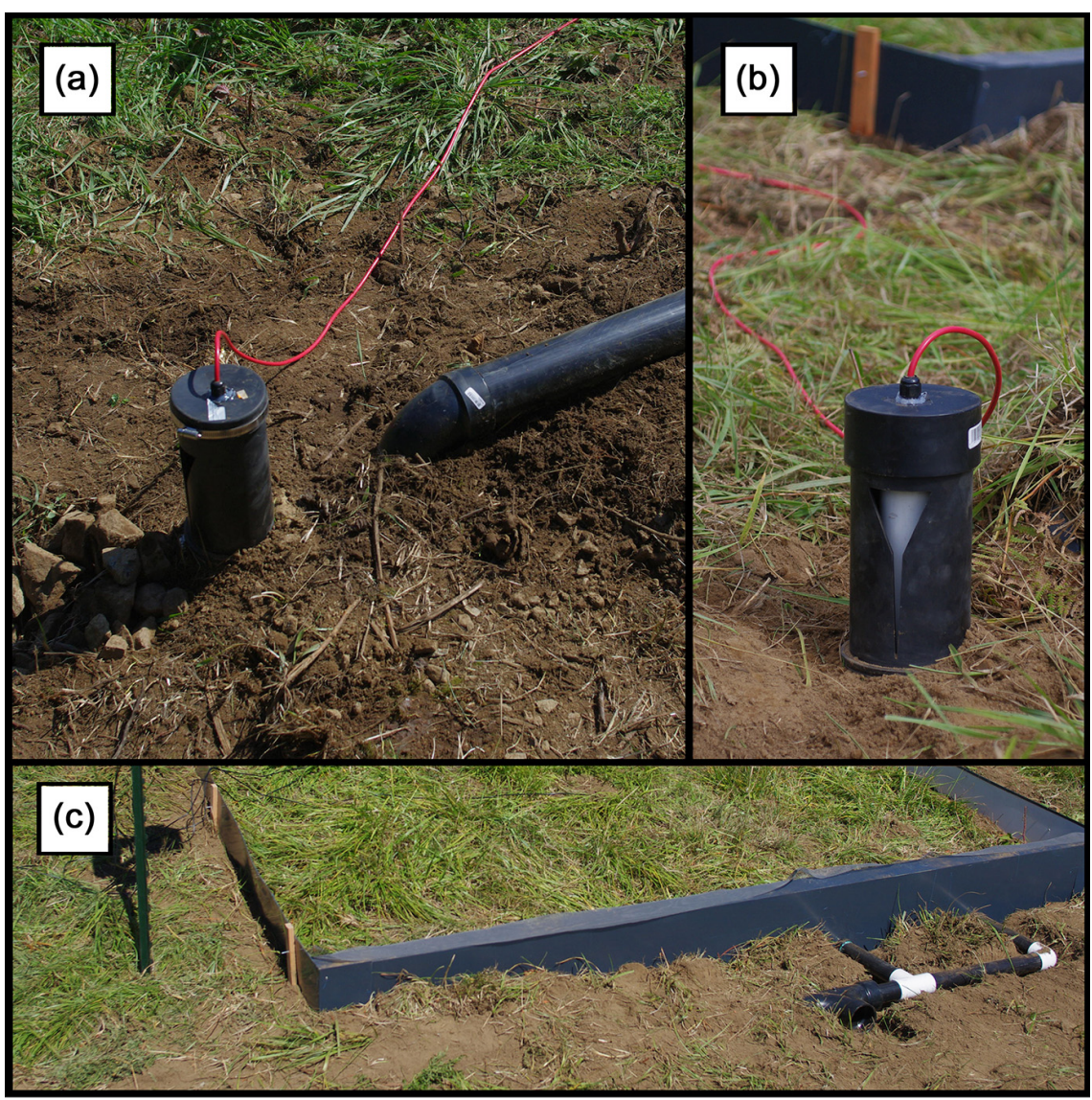

(d)
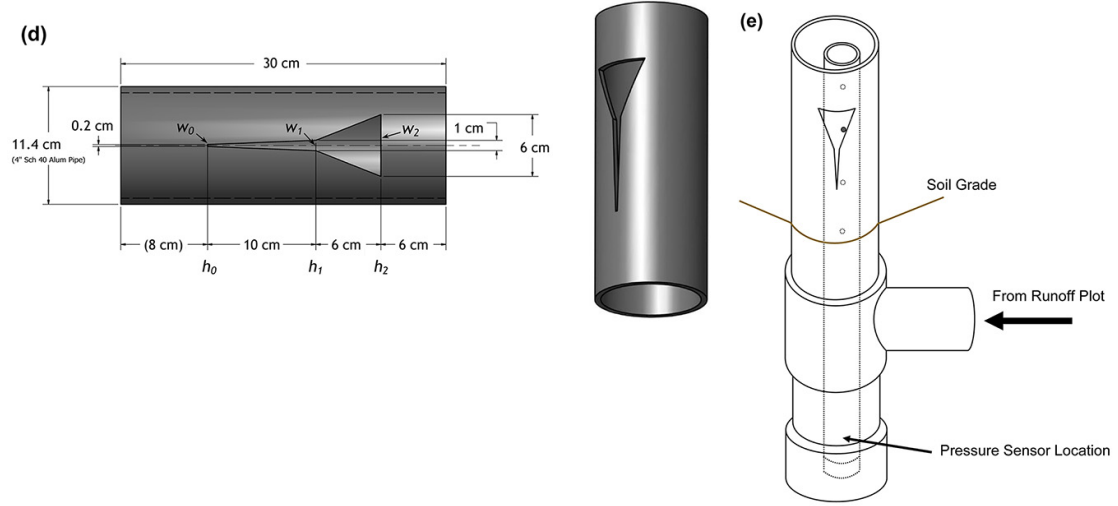

Figure 1. (a, b) Examples of UBeTubes installed below runoff plots; (c) connection between the runoff plots and the UBeTube system; (d) dimensions of the slot as machined (modified with permission from Christopher CNC); and (e) schematic of the instrument setup.

when $h>h_{2}$

$$
\begin{gathered}
Q=\frac{2}{3} c w_{1} \sqrt{2 g}\left(\left(h-h_{1}\right)^{3 / 2}-\left(h-h_{2}\right)^{3 / 2}\right)+c \frac{\left(w_{2}-w_{1}\right)}{\left(h_{2}-h_{1}\right)} \\
\sqrt{2 g}\left(\frac{4}{15}\left(h-h_{1}\right)^{5 / 2}+\frac{2}{5}\left(h-h_{2}\right)^{5 / 2}-\frac{2}{3}\left(h-h_{1}\right)\left(h-h_{2}\right)^{3 / 2}\right), \\
+\frac{2}{3} c w_{0} \sqrt{2 g}\left(h^{3 / 2}-\left(h-h_{1}\right)^{3 / 2}\right)+c \frac{\left(w_{1}-w_{0}\right)}{h_{1}} \sqrt{2 g} \\
\left(\frac{4}{15} h^{5 / 2}+\frac{2}{5}\left(h-h_{1}\right)^{5 / 2}-\frac{2}{3} h\left(h-h_{1}\right)^{3 / 2}\right)
\end{gathered}
$$

where $h$ is the water height, $g$ is the gravitational, $h_{0}$ is the height of the bottom of the slot (bottom of the lower trapezoid), $h_{1}$ is the height of the lower trapezoid, $h_{2}$ is the height of the upper trapezoid, $w_{0}$ is the slot width at the bottom of the lower trapezoid, $w_{1}$ is the slot width at the transition between trapezoids, $w_{2}$ is the width at the top of the upper trapezoid, and $c$ is a calibration factor which accounts for non-ideal behaviors. These dimensions are shown in Fig. 1d.

Water height can be measured through a number of methods; we used a vented pressure transducer system (Decagon Devices CTD) for its combination of low noise, reliability and economy. For our installations, we placed the water level sensor within a pipe located concentrically inside of 
the main tube (Fig. 1e). This second pipe had a diameter of $4.2 \mathrm{~cm}$ (1/4 in. Schedule $40 \mathrm{PVC})$, and was perforated with $0.6 \mathrm{~cm}$ diameter holes beginning $1 \mathrm{~cm}$ below the bottom of the height of the slot. This allowed the inner pipe to act as a stilling well, with the goal of helping to reduce momentum effects on the water level at high flows and to prevent non-suspended sediment from interfering with the sensor.

The rating curve (flow rate, $Q$, versus water height, $h$ ) for the presented design is shown in Fig. 2. Based on a water-level sensor accuracy of $\pm 0.7 \mathrm{~cm}$, the minimum flow needed to exceed the noise threshold is $0.22 \mathrm{~L} \mathrm{~min}^{-1}$. However, increasing the water-level sensor accuracy to $\pm 0.1 \mathrm{~cm}$ decreases the minimum flow requirement to less than $0.05 \mathrm{~L} \mathrm{~min}^{-1}$ and greatly improves the overall accuracy of the instrument (red dotted lines). Thus, the superimposed trapezoid slot design presented in Figs. 1d and 2c can measure a range of flows spanning more than 3 orders of magnitude: from $<0.3$ to $\sim 300 \mathrm{~L} \mathrm{~min}^{-1}$. The minimum flow threshold can be further reduced through optimization of the slot geometry for the expected range of flows; however, very small widths are difficult to machine and are more susceptible to clogging and capillary effects.

The effect of slot width on instrument sensitivity can also be seen by plotting the derivative of the rating curve $(\mathrm{d} Q / \mathrm{d} h)$ against the flow rate $(Q)$ (Fig. 3). The rate of change is steepest in the upper section of the slot, where the width is greatest. Two inflection points can also be seen in the $\mathrm{d} Q / \mathrm{d} h$ line: the first when the water level transitions from the lower to upper trapezoid (i.e., $h_{1}$ ), and the second when the water level goes above the top of the slot (i.e., $h_{2}$ ). Again, optimizing the slot geometry for the expected range of flows can help to increase the instrument sensitivity.

\subsection{Instrument storage}

To calculate inflow into the UBeTube instrument (rather than outflow), it is necessary to quantify the water storage within the instrument itself. We recommend the storage equation provided by Stomph et al. (2002b):

$I_{t}=\left[\frac{S_{t}-S_{t-1}}{\Delta t}\right]+\left[\frac{Q_{t}-Q_{t-1}}{2}\right]$,

$S_{t}=\frac{\pi d^{2} h_{t}}{4}$,

where $I_{t}$ is the inflow into instrument at time $t, S_{t}$ is the storage in flowmeter at time $t, Q_{t}$ is the outflow at time $t, d$ is the pipe diameter, $h_{t}$ is the height of the water within the pipe at time $t$, and $\Delta t$ is the time difference between present $(t)$ and previous observations $(t-1)$.

Equation (4) allows for the near-instantaneous calculation of runoff and can allow for the study of runoff timing and shape of the hydrograph. It also is useful for times when the water level is not precisely at the bottom of the notch, due to evaporation or capillary effects (as discussed in Sect. 4).

\subsection{Instrument calibration}

The instrument was validated using a simple test, where various steady-state flows were added to the system. Five different flow rates were measured across a range of $\sim 2$ to $\sim 40 \mathrm{~L} \mathrm{~min}^{-1}$; for each flow rate the measurement was repeated 3 times, with each repetition lasting $5 \mathrm{~min}$. The flows were generated by a hose connected to a municipal water supply. The actual flow rate was measured before and after each repetition using a $20 \mathrm{~L}$ bucket and a stopwatch to verify that the flow was constant and did not drift during the measurement period.

Based on the mean value for each 5 min repetition, the measurement error ranged from 1 to $25 \%$ (Fig. 4). Error increased as a function of flow rate as momentum effects began to dominate and the instrument response became more sensitive to water height (as demonstrated by the $\mathrm{d} Q / \mathrm{d} h$ curve in Fig. 3). At the same time, our simple bucket-and-stopwatch method for estimating the "true" flow also had greater systematic error at high rates, so it is difficult to determine how much of the observed error was solely attributable to the UBeTube instrument. Future calibration efforts may benefit from a more robust method for determining the true discharge (such as an inline digital flowmeter).

A calibration factor can be included in the calculation of flow rate to account for roughness in the slot surface and deviation from steady-state flow conditions. While a number of different correction factor techniques may be suitable, we found that for this particular design a simple first-order correction factor of

$c=1-\frac{1.4 h}{100}, \quad h<32 \mathrm{~cm}$,

reduced the maximum measurement error of the aforementioned laboratory experiment from 25 to $14 \%$ (Fig. 4) and caused the data to closely follow the theoretical 1:1 line.

\section{Results of field installations}

As part of a long-term study focused on quantifying the efficacy of roadside vegetated filter strips at infiltrating stormwater generated by the impervious areas, six UBeTube instruments were installed at runoff plots around the western part of the state of Oregon. Two of the runoff plots were constructed to be $3 \times 3 \mathrm{~m}$ in dimension, while the other four plots were built to be $3 \times 6 \mathrm{~m}$. The plots were designed so that all overland flow becomes collected at the downslope edge of the plot and then piped into the UBeTube instruments (runoff plots can be seen in Fig. 1a, b and c). Example data showing runoff measured at one of the $3 \times 3 \mathrm{~m}$ (the "Alsea" site) and one of the $3 \times 6 \mathrm{~m}$ (the "Otis" site) runoff plots are shown in Fig. 5. Rainfall data were measured using a Decagon ECRN100 high-resolution rain gauge $(0.2 \mathrm{~mm})$ installed at each site. One-minute measurement intervals were used for the 

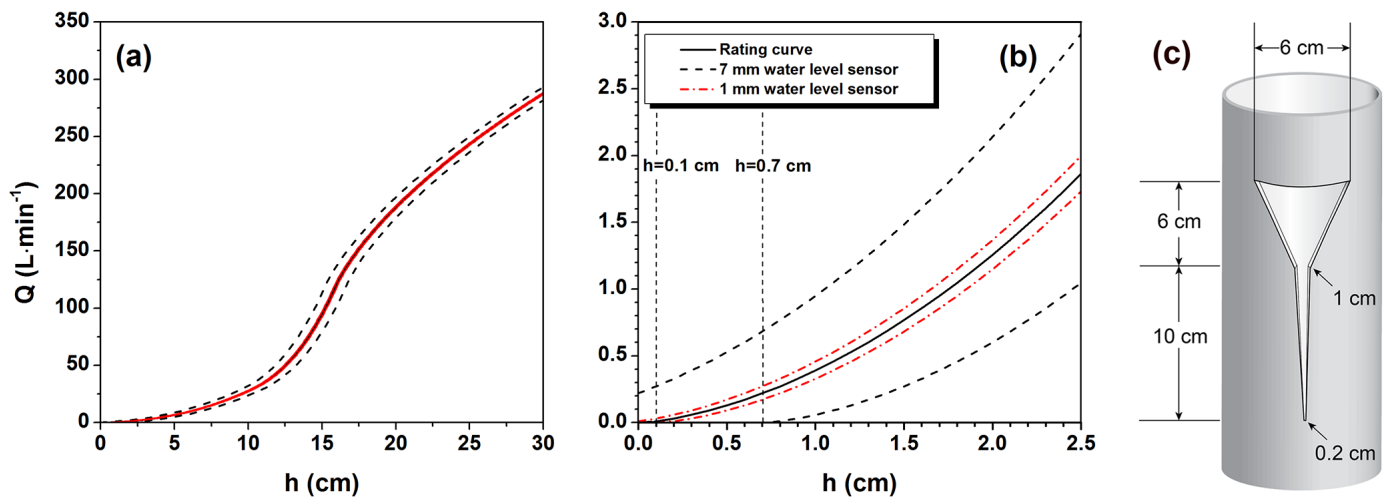

Figure 2. (a) Rating curve for the UBeTube configuration shown in Fig. 1, with $c=0.95$; (b) the low flow $\left(<3 \mathrm{~L} \mathrm{~min}^{-1}\right)$ characteristic of the instrument; and (c) schematic showing the slot geometry. The black dashed lines in (a) and (b) show the expected measurement error due to a $\pm 0.7 \mathrm{~cm}$ water level measurement error within the tube, whereas the red dashed lines show the expected measurement error due to a $\pm 0.1 \mathrm{~cm}$ water level measurement error.

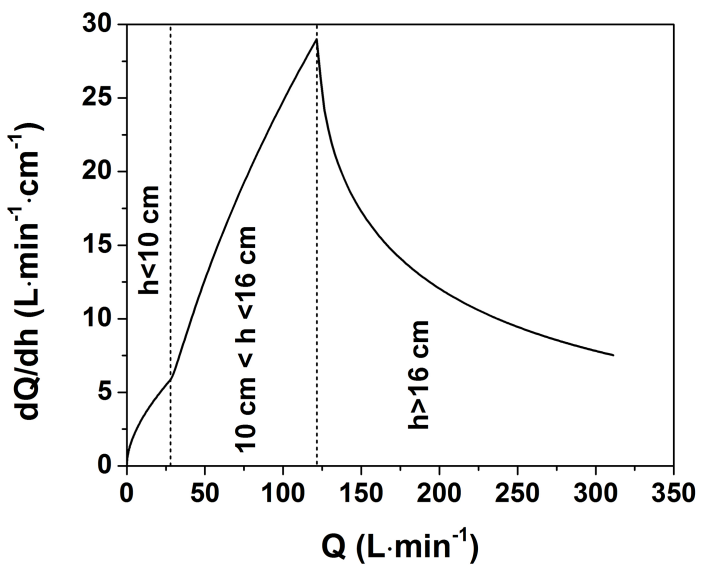

Figure 3. Derivative of the rating curve $(\mathrm{d} Q / \mathrm{d} h)$ plotted against the flow rate $(Q)$. The curve has inflection points at $h=10 \mathrm{~cm}$ (when the water reaches the top of the first trapezoid) and at $h=16 \mathrm{~cm}$ (when the water reaches the top of the slot).

rain gauges and for the pressure transducers within the UBeTube instruments.

As can be seen, not all precipitation events caused a corresponding runoff response. For instance, at the Alsea site (Fig. 5b) the first rainfall event on 5 March 2014 did not produce any measurable runoff, likely due to dry antecedent conditions. However, subsequent rainfall events of approximately the same magnitude produced runoff rates that approached or exceeded the rainfall rate (the latter occurrence due to run-on being delivered from the adjacent highway surface). Moreover, comparing the runoff rates from two examples demonstrates the dynamic range of the UBeTube system, as it proved itself capable of adequately measuring low flows at the Otis site $\left(\sim 0.2 \mathrm{~mm} \mathrm{~h}^{-1}\right)$ and high flows at the Alsea site (up to $40 \mathrm{~mm} \mathrm{~h}^{-1}$ ).

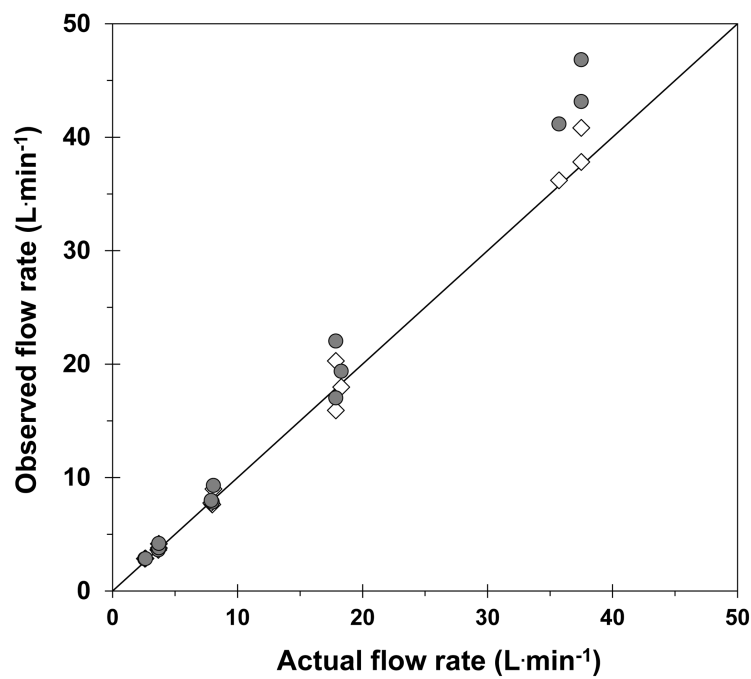

Figure 4. Results of the laboratory validation experiment. The uncorrected measurements are represented by the gray-filled circles, while the measurements corrected using Eq. (5) are represented by the open diamonds. Each point represents the mean flow rate measured over a $5 \mathrm{~min}$ period.

\section{Considerations}

Although the UBeTube instrument has proven its capability in measuring flow for plot- and field-scale experiments, we here list several considerations that practitioners should keep in mind when installing and/or using the instrument, to ensure the quality of collected data:

1. When using the instrument in cold weather, extra attention is needed when the ambient temperature drops close to or below freezing, as ice can form inside of the tube. At the same time, some water level sensors (including the Decagon Devices CTD model used in 

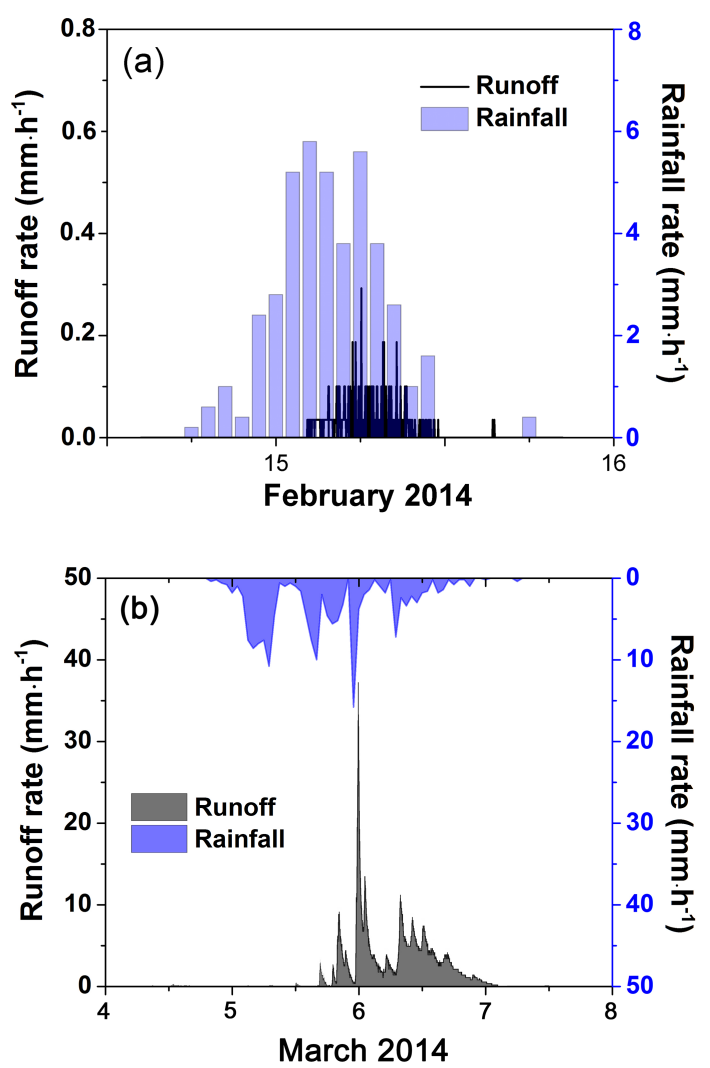

Figure 5. Examples of field applications of the UBeTube instrument in a long-term study measuring highway stormwater runoff produced by highway surfaces within western Oregon. (a) Data come from (a) state highway OR-18 near Otis, Oregon; and (b) state highway OR-34 near Alsea, Oregon. The left $y$ axis shows the runoff rate measured by the instrument, and the right $y$ axis shows the natural rainfall rate as measured by tipping bucket rain gauges installed at the sites.

our example system) can become damaged if the water around/within them freezes. While installing the sensor below grade (as shown in Fig. 1e) should provide some protection from freezing, we nonetheless recommend field inspection of the installation before and/or after snow events to ensure the quality of data and to verify proper operation of the water level sensor (Fig. 6a).

2. Under ideal conditions, the water level inside the tube would be maintained at the bottom of the thin slot so that whenever there is an inflow event, the water will flow out of the tube instantaneously. However, this can be difficult to achieve in field installations due to water films forming in the slot due to capillary rise (Fig. 6b) or inevitable water loss from evaporation (Fig. 6c). Therefore, the tube should either be refilled to the outlet level prior to expected flow events, or a calibration should be developed to account for flows that occur before the water level reaches the bottom of the slot. Equation (4),

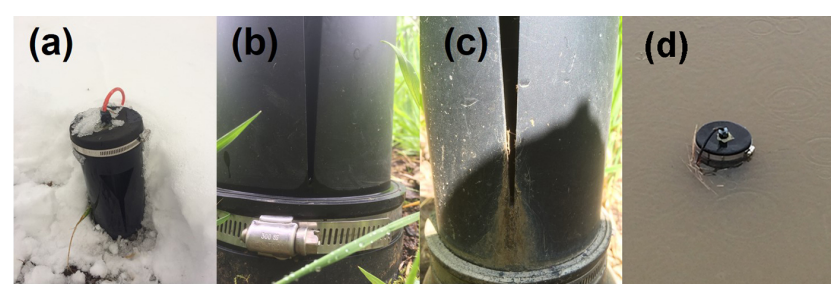

Figure 6. (a) Field inspection of the UBeTube after snow event; (b) capillary water film in the slot; (c) evaporation of water from the tube during dry periods and the clogging of flow path by sediments and dirt; (d) submersion of the tube in the water after snowmelt and subsequent rainfall.

which accounts for storage within the instrument, can also be used in such instances.

3. As water flows into the tube, it will carry sediments and small debris that can pass through the filter mesh installed at the front edge of the collection channel. These sediments and debris can be accumulated in the thin slot and block the flow path, thus, jeopardizing the reliability of data (Fig. 6c). Regular cleaning may be necessary.

4. The presence of suspended sediment within the stilling well could increase the fluid density and, thus, cause measurement error. In high sediment environments it may therefore be necessary to account for this effect and/or use alternative methods for measuring water level, such as capacitance probes.

5. When the UBeTube is installed at places where stormwater runoff does not quickly drain (e.g., at the bottom of a roadside vegetated swale), it is exposed to the risk of being flooded (Fig. 6d), which will prevent the collection of reliable data until the surrounding area drains.

6. Momentum effects can cause pressure fluctuations in both the water level and in the pressure measurements. These effects become more prominent as the flow rates increase, as seen in Fig. 4. Therefore, it is important to have a carefully designed stilling well that can help alleviate some of the higher-frequency fluctuations. The use of alternative (non-pressure) water level sensors, such as capacitance probes, may also reduce error from momentum effects. Moreover, as previously mentioned, such sensors might also be preferable in high sediment systems.

\section{Conclusions}

Hydrological studies require accurate measurement of water balance components such as runoff. We presented a new instrument, called the UBeTube, which can monitor runoff 
flows at the plot scale. The design is small, sturdy (no moving parts), and can measure both low $\left(\sim 0.05 \mathrm{~L} \mathrm{~min}^{-1}\right)$ and high $\left(\sim 300 \mathrm{~L} \mathrm{~min}^{-1}\right)$ flows, with increased range possible depending on the configuration of the instrument. The instrument is capable of high accuracy, dependent on the resolution and accuracy of the measurement of water level within the instrument. Our laboratory measurements showed the error ranging from 1 to $25 \%$ (over a flow rate range of 2 $40 \mathrm{~L} \mathrm{~min}^{-1}$ ), which could be reduced to $<14 \%$ with a simple first-order correction. Additional reductions in error can likely be attained by using a combination of more accurate pressure sensors, more robust correction factors, and/or by optimizing the slot geometry to the expected conditions.

Most important, the instrument is low-cost, as a single instrument can be manufactured and installed for less than USD 150 (not including water measurement sensor and datalogging costs). The instrument has thus far been used in two field-based studies, providing multiple years of nearcontinuous runoff data. We presented sample plot-scale data showing that the instrument is capable of providing reliable, near-continuous measurements of surface runoff. Overall, the combination of reliability, accuracy and affordability makes the UBeTube a practical choice for measuring runoff.

Acknowledgements. This work was performed under two grants: National Science Foundation award 0943682, and Oregon Department of Transportation award 13-025. The authors would like to acknowledge the contributions of Majdi Abou Najm of the American University of Beirut, Jon Hesseltine and Zane Rogers of Oregon State University, and recognize Frank Selker of Selkermetrics, LLC, for sparking the original idea that lead to the development of this instrument. Finally, we would like to thank Kevin Christopher of Christopher CNC for his assistance and patience in prototyping the instrument.

Edited by: A. Benedetto

\section{References}

Aksoy, H. and Kavvas, M. L.: A review of hillslope and watershed scale erosion and sediment transport models, Catena, 64, 247271, 2005.

Ali, G., Oswald, C. J., Spence, C., Cammeraat, E. L., McGuire, K. J., Meixner, T., and Reaney, S. M.: Towards a unified thresholdbased hydrological theory: necessary components and recurring challenges, Hydrol. Process., 27, 313-318, 2013.

Betson, R. P.: What is watershed runoff?, J. Geophys. Res., 69, 1541-1552, 1964.

Blair, A., Sanger, D., White, D., Holland, A. F., Vandiver, L., Bowker, C., and White, S.: Quantifying and simulating stormwater runoff in watersheds, Hydrol. Process., 28, 559-569, 2014.

Blume, T., Zehe, E., Reusser, D. E., Iroumé, A., and Bronstert, A.: Investigation of runoff generation in a pristine, poorly gauged catchment in the Chilean Andes I: A multi-method experimental study, Hydrol. Process., 22, 3661-3675, 2008.
Butler, D. M., Franklin, D. H., Cabrera, M. L., Tasistro, A. S., Xia, K., and West, L. T.: Evaluating aeration techniques for decreasing phosphorus export from grasslands receiving manure, J. Environ. Qual., 37, 1279-1287, 2008.

Descroix, L., Viramontes, D., Estrada, J., Gonzalez Barrios, J.-L., and Asseline, J.: Investigating the spatial and temporal boundaries of Hortonian and Hewlettian runoff in Northern Mexico, J. Hydrol., 346, 144-158, 2007.

Dosskey, M. G., Hoagland, K. D., and Brandle, J. R.: Change in filter strip performance over ten years, J. Soil Water Conserv., 62, 21-32, 2007.

Dunne, T. and Black, R. D.: Partial area contributions to storm runoff in a small New England watershed, Water Resour. Res., 6, 1296-1311, 1970.

Goodrich, D., Schmugge, T., Jackson, T., Unkrich, C., Keefer, T., Parry, R., Bach, L., and Amer, S.: Runoff simulation sensitivity to remotely sensed initial soil water content, Water Resour. Res., 30, 1393-1405, 1994.

Habib, E., Krajewski, W. F., and Kruger, A.: Sampling errors of tipping-bucket rain gauge measurements, J. Hydrol. Eng., 6, 159-166, 2001.

Hashim, G. M., Ciesiolka, C. A. A., Yusoff, W. A., Nafis, A. W., Mispan, M. R., Rose, C. W., and Coughlan, K. J.: Soil erosion processes in sloping land in the east coast of Peninsular Malaysia, Soil Tech., 8, 215-233, 1995.

Hewlett, J. D. and Hibbert, A. R.: Factors affecting the response of small watersheds to precipitation in humid areas, Forest Hydrol., 1967, 275-290, 1967.

Horton, R. E.: Analysis of runoff-plat experiments with varying infiltration-capacity, Trans., Amer. Geophys. Union, 20, 693711, 1939.

Hudson, N. W.: Field measurement of soil erosion and runoff, FAO, Rome, Italy, 1993.

Humphrey, M., Istok, J., Lee, J., Hevesi, J., and Flint, A.: A new method for automated dynamic calibration of tipping-bucket rain gauges, J. Atmos. Ocean. Tech., 14, 1513-1519, 1997.

Jones, O. D., Sheridan, G. J., and Lane, P. N.: Using queuing theory to describe steady-state runoff-runon phenomena and connectivity under spatially variable conditions, Water Resour. Res., 49, 7487-7497, 2013.

McDonnell, J. J.: Where does water go when it rains? Moving beyond the variable source area concept of rainfall-runoff response, Hydrol. Process., 17, 1869-1875, 2003.

McGuire, K. J. and McDonnell, J. J.: Hydrological connectivity of hillslopes and streams: Characteristic time scales and nonlinearities, Water Resour. Res., 46, W10543, doi:10.1029/2010WR009341, 2010.

Meals, D. W. and Braun, D. C.: Demonstration of Methods to Reduce Runoff from Dairy Manure Application Sites, J. Environ. Qual., 35, 1088-1100, 2006.

Nearing, M., Wei, H., Stone, J., Pierson, F., Spaeth, K., Weltz, M., Flanagan, D., and Hernandez, M.: A rangeland hydrology and erosion model, Trans. ASABE, 54, 1-8, 2011.

Nehls, T., Nam Rim, Y., and Wessolek, G.: Technical note on measuring run-off dynamics from pavements using a new device: the weighable tipping bucket, Hydrol. Earth Syst. Sci., 15, 13791386, doi:10.5194/hess-15-1379-2011, 2011. 
Nystuen, J. A.: Relative performance of automatic rain gauges under different rainfall conditions, J. Atmosph. Ocean. Tech., 16, 1025-1043, 1999.

Nystuen, J. A., Proni, J. R., Black, P. G., and Wilkerson, J. C.: A comparison of automatic rain gauges, J. Atmos. Ocean. Tech., 13, 62-73, 1996.

Pinson, W., Yoder, D., Buchanan, J., Wright, W., and Wilkerson, J.: Design and evaluation of an improved flow divider for sampling runoff plots, Appl. Eng. Agric., 20, 433-438, 2004.

Radatz, T. F., Thompson, A. M., and Madison, F. W.: Soil moisture and rainfall intensity thresholds for runoff generation in southwestern Wisconsin agricultural watersheds, Hydrol. Process., 27, 3521-3534, 2013.

Srinivasan, M., Wittman, M., Hamlett, J., and Gburek, W.: Surface and subsurface sensors to record variable runoff generation areas, Trans. ASAE, 43, 651-660, 2000.

Steenhuis, T. S., Hrnčǐŕ, M., Poteau, D., Romero Luna, E. J., Tilahun, S. A., Caballero, L. A., Guzman, C. D., Stoof, C. R., Šanda, M., Yitaferu, B., and Císlerová, M.: A Saturated Excess Runoff Pedotransfer Function for Vegetated Watersheds, Vadose Zone J., 12, 1-10, doi:10.2136/vzj2013.03.0060, 2013.

Stewart, R. D., Hut, R., Rupp, D. E., Gupta, H., and Selker, J. S.: A resonating rainfall and evaporation recorder, Water Resour. Res., 48, W08601, doi:10.1029/2011WR011529, 2012.
Stewart, R. D., Abou Najm, M. R., Rupp, D. E., Lane, J. W., Uribe, H. C., Arumí, J. L., and Selker, J. S.: Hillslope runoff thresholds with shrink-swell clay soils, Hydrol. Process., 29, 557-571, 2014.

Stomph, T., De Ridder, N., and Van de Giesen, N.: A flume design for the study of slope length effects on runoff, Earth Surf. Process. Landf., 26, 647-655, 2001.

Stomph, T., De Ridder, N., Steenhuis, T., and Van de Giesen, N.: Scale effects of Hortonian overland flow and rainfall-runoff dynamics: Laboratory validation of a process-based model, Earth Surf. Process. Landf., 27, 847-855, 2002a.

Stomph, T., De Ridder, N., and Van de Giesen, N.: A flowmeter for low discharges of laboratory flumes, Trans. ASAE, 45, 345-349, $2002 b$.

Van de Giesen, N., Stomph, T., and De Ridder, N.: Scale effects of Hortonian overland flow and rainfall-runoff dynamics in a West African catena landscape, Hydrol. Process., 14, 165-175, 2000.

Yu, B., Rose, C. W., Coughlan, K., and Fentie, B.: Plot-scale rainfall-runoff characteristics and modeling at six sites in Australia and Southeast Asia, Trans. ASAE, 40, 1295-1303, 1997.

Zhao, S., Dorsey, E., Gupta, S., Moncrief, J., and Huggins, D.: Automated water sampling and flow measuring devices for runoff and subsurface drainage, J. Soil Water Conserv., 56, 299-306, 2001 . 